\title{
Biocompatibility and antibacterial activity of nitrogen-doped titanium dioxide nanoparticles for use in dental resin formulations
}

This article was published in the following Dove Press journal:

International Journal of Nanomedicine

5 December 2016

Number of times this article has been viewed

\author{
Andrew Zane' \\ Ranfang Zuo ${ }^{2}$ \\ Frederick A Villamena ${ }^{3}$ \\ Antal Rockenbauer ${ }^{4,5}$ \\ Ann Marie Digeorge \\ Foushee' \\ Kristin Flores' \\ Prabir K Dutta ${ }^{2}$ \\ Amber Nagy'
}

'Biomaterials and Environmental Surveillance Department, Naval Medical Research Unit San

Antonio, Joint Base San Antonio, Fort Sam Houston, San Antonio,

TX, ${ }^{2}$ Department of Chemistry and Biochemistry, ${ }^{3}$ Department of Biological Chemistry and Pharmacology, Davis Heart and Lung Research Institute, College of Medicine, The Ohio State University, Columbus, OH, USA; ${ }^{4}$ Research Centre for Natural Sciences of the Hungarian Academy of Sciences, Institute of Materials and Environmental Chemistry, ${ }^{5}$ Department of Physics, MTA-BME Condensed Matter Research Group, Budapest University of Technology and Economics, Budapest, Hungary

Correspondence: Amber Nagy Naval Medical Research Unit San Antonio, 3650 Chambers Pass, JBSA Ft. Sam Houston, San Antonio, TX 78234, USA

Tel +I 210 5397017

Email amber.m.mallory2.civ@mail.mil

\begin{abstract}
The addition of antibacterial functionality to dental resins presents an opportunity to extend their useful lifetime by reducing secondary caries caused by bacterial recolonization. In this study, the potential efficacy of nitrogen-doped titanium dioxide nanoparticles for this purpose was determined. Nitrogen doping was carried out to extend the ultraviolet absorbance into longer wavelength blue light for increased biocompatibility. Titanium dioxide nanoparticles (approximately 20-30 nm) were synthesized with and without nitrogen doping using a sol-gel method. Ultraviolet-Visible spectroscopy indicated a band of trap states, with increasing blue light absorbance as the concentration of the nitrogen dopant increased. Electron paramagnetic resonance measurements indicated the formation of superoxide and hydroxyl radicals upon particle exposure to visible light and oxygen. The particles were significantly toxic to Escherichia coli in a dose-dependent manner after a 1-hour exposure to a blue light source $(480 \mathrm{~nm})$. Intracellular reactive oxygen species assay demonstrated that the particles caused a stress response in human gingival epithelial cells when exposed to 1 hour of blue light, though this did not result in detectable release of cytokines. No decrease in cell viability was observed by water-soluble tetrazolium dye assay. The results show that nitrogen-doped titanium dioxide nanoparticles have antibacterial activity when exposed to blue light, and are biocompatible at these concentrations.
\end{abstract}

Keywords: titanium dioxide, antibacterial activity, nitrogen doping

\section{Introduction}

Despite the long-term environmental and human health concerns related primarily to mercury, amalgam dental restorations are still widely used. This is due to their enhanced durability over composite resins, particularly in the case of large restorations placed in molars. ${ }^{1}$ Failure of composite resin restorations is typically the result of two major factors: errors during placement, such as inadequate or uneven curing, and secondary caries caused by shrinkage and breakage of the material leading to colonization of biofilm-forming bacteria in the resin-dentin interface. ${ }^{2}$ A 2003 review $^{3}$ found that these failures are due to improper placement technique or incorrect choice of materials when they occur within the first 5 years after placement. Failures occurring between 5 and 17 years are typically the result of secondary caries. Overall failure rates during this time period are as high as $45 \% .^{3}$

The acidic conditions associated with secondary caries primarily affect the remaining tooth, but not the restoration material. ${ }^{4}$ Streptococcus mutans biofilms grown on a resin-dentin interface cause a significant reduction in fatigue resistance of the joint material due to degradation of dentin at the resin-dentin interface. ${ }^{5}$ The incorporation 
of an antibacterial agent into this region, which is inaccessible during typical oral prophylaxis, will reduce dental restoration failure and increase their effective lifetime. Traditional organic molecules used as antibacterial agents are not ideal for this application, as they have limited stability and lifetimes. Inorganic materials with antibacterial activity have generally longer usable lifetimes, and thus have greater potential for successful use in this case.

The development of nanomaterials, materials smaller than $100 \mathrm{~nm}$ in at least one dimension, has resulted in advancements in many fields, including the improvement of antibacterial and "self-cleaning" properties of materials such as concrete ${ }^{6}$ glass, ${ }^{7}$ and medical devices and materials. ${ }^{8-10}$ $\mathrm{TiO}_{2}$ has been extensively used in the development of these materials due to photocatalytic activity stimulated by ultraviolet (UV) light exposure. Upon excitation with UV light, $\mathrm{TiO}_{2}$ generates reactive oxygen species (ROS) in the presence of water. ${ }^{11}$ The ROS generated in this reaction lead to the decomposition of organic compounds ${ }^{11}$ and have demonstrated antibacterial activity toward several bacterial strains including Escherichia coli, Pseudomonas aeruginosa, and Staphylococcus aureus. ${ }^{12-14}$

Nanoparticles, primarily silica and zirconium oxide, are currently used in dental composite resins to increase the strength properties while reducing material shrinkage during curing. ${ }^{15}$ There is a clear opportunity to replace these with functionalized nanomaterials that could impart additional benefits, such as antibacterial $\mathrm{TiO}_{2}$. Recently, an antibacterial composite was developed that also had self-healing and remineralization properties using calcium phosphate nanoparticles. ${ }^{16}$ Another self-healing composite material was developed using breakable capsules of unreacted monomers, which has shown promising healing characteristics. ${ }^{17}$

Recent research has shown that the light absorption of $\mathrm{TiO}_{2}$ can be shifted to the visible range by doping with a variety of atoms, including nitrogen, ${ }^{18-21}$ fluorine, ${ }^{22}$ copper, ${ }^{23}$ and silver, ${ }^{24}$ resulting in a new class of visible light active materials. This is of particular interest in the development of novel dental materials for two reasons: exposure of gum tissue to blue light is preferable to cytotoxic UV light ${ }^{25}$ and most of the dental offices are already equipped with blue light sources used to cure photoactive composite dental resins. The incorporation of blue light-sensitive $\mathrm{TiO}_{2}$ into a dental material could allow for long-term and repeatable release of antibacterial ROS. This is currently not possible with traditional commercially available organic antibiotics, which are consumed upon use.
Techniques for doping of $\mathrm{TiO}_{2}$ to increase the UV and visible light sensitivity initially utilized metals. This was generally unsuccessful due to issues with reproducibility and lack of photocatalytic activity at visible wavelengths, attributed to high carrier recombination rates. ${ }^{26}$ Later, nonmetaldoped $\mathrm{TiO}_{2}$ was developed, primarily with nitrogen, which is to date the most successful and widely utilized dopant for the visible light sensitization of titania. ${ }^{27}$ Nitrogen-doped $\mathrm{TiO}_{2}$ with codopants such as silver has also been developed with promising characteristics. ${ }^{24}$ Metal dopants or codopants are, however, not ideal for eventual clinical use due to the potential for metal leaching and toxicity to the surrounding tissue when used at concentrations necessary for killing pathogenic bacteria. ${ }^{28,29}$

In this report, nitrogen-doped $\mathrm{TiO}_{2}$ particles $\left(\mathrm{N}-\mathrm{TiO}_{2}\right.$ NPs) were synthesized based on a representative literature source $^{18}$ for potential incorporation into a novel dental resin material with light-activated antibacterial properties. $\mathrm{N}-\mathrm{TiO}_{2}$ NPs were extensively characterized by various techniques. To determine if the particles are appropriate for further study toward this application, their toxicity under blue light (485 nm) exposure to a model bacterium, E. coli, and their biocompatibility with human gingival epithelial cells (hGEPs) were examined.

\section{Methods}

\section{Chemical synthesis and characterization} $\mathrm{N}-\mathrm{TiO}_{2}$ synthesis

Synthesis of $\mathrm{N}-\mathrm{TiO}_{2} \mathrm{NPs}$ was adapted from a recent literature synthesis, ${ }^{18}$ wherein a sol-gel synthesis of $\mathrm{TiO}_{2}$ was modified to add ethylmethylamine as a nitrogen source.

Titanium isopropoxide, anhydrous ethanol, hydrogen peroxide $(30 \%, \mathrm{w} / \mathrm{v})$, and ethylmethylamine were all purchased from Sigma Aldrich and used without further purification. The water used in the procedure was purified by a Millipore Milli-Q Advantage A-10 Water Purification System.

Titanium tetraisopropoxide ( $5 \mathrm{~g}$ ) was first added to $10 \mathrm{~mL}$ anhydrous ethanol in a dry inert (nitrogen) environment. This mixture was added to $50 \mathrm{~mL}$ of water while stirring $(600 \mathrm{rpm})$, which forms a white $\mathrm{TiO}_{2}$ precipitate instantaneously. Stirring was continued for an additional 10 minutes after which point the precipitate was washed with water three times by centrifugation $(5,000 \times g)$.

In a fume hood, $10 \mathrm{~mL}$ of $30 \%(\mathrm{w} / \mathrm{v})$ hydrogen peroxide was added to the washed precipitate while stirring (600 rpm), which results in the formation of an orange transparent solution after several minutes. After dissolution, $0.104 \mathrm{~g}$ ethylmethylamine was added and the solution was then stirred 
overnight until it thickened into a gel. The gel was dried for 24 hours at $100^{\circ} \mathrm{C}$, and then ground into a powder using a mortar and pestle. The resulting powder was then calcined at $300^{\circ} \mathrm{C}$ in a muffle furnace for 24 hours. To determine the impact of nitrogen precursor concentration on doping levels, the amount of ethylmethylamine added was varied as $0,0.104$, 0.130 , and $0.156 \mathrm{~g}$. The final samples were labeled $1,1.25$, and $1.5 \mathrm{~N}-\mathrm{TiO}_{2}$, respectively, signifying the relative amount of nitrogen added based on the literature synthesis. ${ }^{18}$

Importantly, care should be taken, particularly at higher concentrations of ethylmethylamine or if attempting to scale up this synthesis, as ethylmethylamine is unstable and ignitable. While the $1.5 \mathrm{~N}-\mathrm{TiO}_{2} \mathrm{NP}$ sample was found to absorb the most visible light, a subsequent batch of these particles ignited during the calcination step, presumably due to an excess of unreacted ethylmethylamine. Also, $1.25 \mathrm{~N}^{-\mathrm{TiO}_{2}}$ NPs were synthesized without any untoward incident, and the majority of experiments detailed below were carried out with this nitrogen loading ratio. When scaling up the synthesis, this issue could potentially occur at lower ethylmethylamine concentrations without proper ventilation.

\section{Particle characterization}

Diffuse reflectance UV-Visible (UV-Vis) absorption spectra of all samples were recorded from 400 to $800 \mathrm{~nm}$ using a Shimadzu UV-2501PC spectrophotometer with ISR-2200 diffuse reflectance attachment.

Zeta potential measurements were recorded with a Malvern Zetasizer Nano ZS. The $\mathrm{pH}$ titrations were performed with an attached MPT-2 titrator supplied with $1 \mathrm{M}$ hydrochloric acid. Titration samples were preadjusted to a $\mathrm{pH}$ between 11 and 12 by adding $1 \mathrm{M}$ sodium hydroxide dropwise, sonicated, and allowed to rest for 30 minutes. Three zeta potential measurements were taken at approximately $0.2 \mathrm{pH}$ unit intervals between $\mathrm{pH} 11$ and 4, with 30 seconds resting time between each measurement. Zeta potential measurements include a minimum of 10 runs in monomodal mode and were analyzed using Smoluchowski model.

High-resolution transmission electron microscopy (TEM) images were obtained using a Tecnai-F20 system. Particles were washed twice by centrifugation and replacement of supernatant with deionized water. The particles were then suspended in a dilute ethanol solution and deposited onto lacey carbon-coated copper grids. Primary particle sizes were evaluated using ImageJ software, measuring at least 50 particles for each sample.

Electron paramagnetic resonance (EPR) spectroscopic measurements were carried out on a Bruker X-band spectrometer with a high-sensitivity resonator at room temperature. General instrument settings were as follows: microwave power, $10 \mathrm{~mW}$; modulation amplitude, $1 \mathrm{G}$; receiver gain $1 \times 10^{5}$; time constant, 82 milliseconds; and time sweep, 42 seconds. Using the spin trap, 5,5-dimethyl-1-pyrroline- $N$-oxide (DMPO), radical adducts were identified from dispersed particles in both aqueous and dimethyl sulfoxide (DMSO) solutions. ${ }^{30}$ In a typical experiment, approximately 13-14 mg of doped $1.25 \mathrm{~N}_{-} \mathrm{TiO}_{2}$ in $100 \mu \mathrm{L}$ distilled water or DMSO suspension was prepared. Equal volumes $(25 \mu \mathrm{L})$ of $\mathrm{TiO}_{2}$ suspension (aqueous or in DMSO) and DMPO solution were thoroughly mixed to give a final DMPO concentration of $100 \mathrm{mM}$. For DMSO experiments, the suspension was bubbled with air, oxygen, or argon for 5 minutes. The resulting suspensions were transferred to $50 \mu \mathrm{L}$ capillary tubes and placed inside the sample cavity. The suspensions were irradiated inside the sample cavity using a fiber-optic $150 \mathrm{~W}$ quartz halogen visible light source. The hyperfine splitting constants of the spin adducts were determined by simulating the spectra using an automatic fitting program. ${ }^{31}$

Powder X-ray diffraction patterns of doped and undoped $\mathrm{TiO}_{2}$ NPs were collected on a Rigaku Geigerflex diffractometer using Ni-filtered $\mathrm{Cu} \mathrm{K} \alpha$ radiation at $40 \mathrm{kV}$ and $25 \mathrm{~mA}$ at $2 \theta$ from $20^{\circ}$ to $70^{\circ}$.

\section{Biological studies}

\section{Cell culture and $\mathrm{N}-\mathrm{TiO}_{2} \mathrm{NP}$ exposures}

Pooled primary hGEPs were purchased from CellnTec Advanced Cell Systems AG (Stauffacherstr, Switzerland) and propagated in CnT-Prime epithelial culture medium (CellnTec Advanced Cell Systems AG) on $100 \mathrm{~mm}$ petri dishes coated with $30 \mu \mathrm{g} / \mathrm{mL}$ Type I rat tail collagen (BD Biosciences, Bedford, MA, USA) diluted in Dulbecco's phosphate-buffered saline. This cell type was chosen since

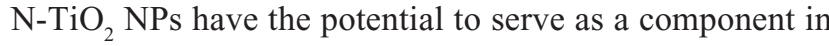
dental resin formulations, thereby putting them in close contact with hGEPs. Cells were passaged when they reached $70 \%-90 \%$ confluency. For routine cultivation, the medium was changed approximately every 3 days. For viability and ROS production assays, cells from passages 3-7 were seeded at $2.5 \times 10^{4}$ cells per well in 96-well flat-bottomed tissue culture plates and acclimated overnight at $37^{\circ} \mathrm{C}, 5 \%$ $\mathrm{CO}_{2}$ before $\mathrm{N}-\mathrm{TiO}_{2} \mathrm{NP}$ exposure. $\mathrm{N}-\mathrm{TiO}_{2}$ NPs at 50, 100, and $200 \mu \mathrm{g} / \mathrm{mL}$ concentration were prepared in CnT-Prime media along with appropriate controls and added immediately to aspirated wells. Cells and nanoparticles were exposed to $485 \mathrm{~nm}$ at a constant power of $12.85 \mathrm{~mW} / \mathrm{cm}^{2}$ and a distance of $55 \mathrm{~mm}$ or ambient light for 60 minutes. 
Temperatures for both light exposure conditions ranged between $30^{\circ} \mathrm{C}$ and $34^{\circ} \mathrm{C}$. Biological experiments were performed with $\mathrm{N}-\mathrm{TiO}_{2}$ only as $\mathrm{TiO}_{2} \mathrm{NPs}$ did not show absorption in the blue light range.

\section{Cell viability assays}

Mitochondrial activity in hGEPs, as measured using watersoluble tetrazolium dye (WST-1) (Roche, Indianapolis, IN, USA), was assessed after incubation with no NPs (negative control), $\mathrm{N}-\mathrm{TiO}_{2} \mathrm{NPs}$, or $1 \%$ Triton $\mathrm{X}$ (positive control) following 60-minute light exposure. After removal of $\mathrm{N}-\mathrm{TiO}_{2}$ NPs by aspiration and culture media replenishment, WST-1 reagent was added to each well $(10 \mu \mathrm{L})$ of 96 -well plates. The plates were briefly tapped to ensure homogeneous reagent mixture and then incubated at $37^{\circ} \mathrm{C}$ and $5 \% \mathrm{CO}_{2}$ for 2 hours before reading at an absorbance wavelength of $440 \mathrm{~nm}$ and a reference wavelength of $600 \mathrm{~nm}$.

\section{Oxidative stress}

ROS formation in hGEPs exposed to increasing concentrations of $\mathrm{N}-\mathrm{TiO}_{2}$ NPs was quantified using 5-(and-6)-carboxy$2^{\prime}, 7^{\prime}$-dichlorodihydrofluorescein diacetate, acetyl ester (CM-H DCFDA) (Molecular Probes, Eugene, OR, USA). hGEPs exposed to Dulbecco's phosphate-buffered saline only or $\mathrm{H}_{2} \mathrm{O}_{2}$ served as controls. N-TiO 2 NPs at all concentrations were included in wells without cells to determine potential induction of spontaneous fluorescence of CM$\mathrm{H}_{2}$ DCFDA. Fluorescence was measured immediately after light exposures using an excitation wavelength of $490 \mathrm{~nm}$ and an emission wavelength of $535 \mathrm{~nm}$ at 0,30 , and 60 minutes postexposure.

\section{$\mathrm{N}-\mathrm{TiO}_{2} \mathrm{NP}$ antibacterial activity against $E$. coli}

The goal of this research was to test the antibacterial activity of $\mathrm{N}-\mathrm{TiO}_{2} \mathrm{NPs}$ in suspension before moving onto more complex biofilm models. Although E. coli is rarely associated with caries formation, other Gram-negative bacteria such as Porphyromonas gingivalis are frequently found in the oral cavity and can cause certain oral diseases, including gingivitis. Therefore, E. coli was chosen as a model bacterium to represent Gram-negative bacteria. Bacterial suspensions of E. coli were grown overnight in lysogeny broth (LB) media and diluted to an approximate concentration of $1 \times 10^{5}$ colony forming units/mL in phosphate-buffered saline (PBS). The suspended bacteria were plated in triplicate with the concentrations of particles ranging from 0 to $200 \mu \mathrm{g} / \mathrm{mL}$. The bacteria were then exposed to ambient room light for 60 minutes as a control or to $485 \mathrm{~nm}$ at a constant power of $12.85 \mathrm{~mW} / \mathrm{cm}^{2}$ and a distance of $55 \mathrm{~mm}$ inside a custom-made light box. After light exposures, the bacteria were recovered for 5 hours at $37^{\circ} \mathrm{C}$, serially diluted in PBS, and plated on LB agar plates for colony count measurements.

For confocal microscopy experiments, E. coli were suspended at a concentration of $1 \times 10^{5}$ colony forming units $/ \mathrm{mL}$ in 24-well plates in LB media. Bacteria were then pelleted, aspirated, and resuspended with $\mathrm{N}-\mathrm{TiO}_{2} \mathrm{NPs}$ suspended in LB media at a concentration of 50, 100, and $200 \mu \mathrm{g} / \mathrm{mL}$. The plates were exposed to ambient or blue light (as described above) for 60 minutes. Bacteria were then stained with LIVE/ DEAD $^{\circledR}$ BacLight stain (Life Technologies, Philadelphia, PA, USA) by incubating them with 1:1 ratios of propidium iodide and SYTO 9 in LB media for 30 minutes in the dark before imaging with a Nikon Eclipse TE-2000E confocal microscope. In the confocal images, green staining is indicative of viable bacteria, whereas red staining represents dead bacteria.

\section{Statistical analyses}

All hGEP and E. coli experiments were repeated three independent times, with a minimum of three technical replicates per experiment.

Statistical comparisons were performed using GraphPad Prism 6 (GraphPad Software, Inc., La Jolla, CA, USA). Two-way analysis of variance with Tukey's multiple comparisons tests were used to determine if significant changes existed between light treatments as well as NP doses. Data were represented as mean \pm standard deviation. Data were considered statistically significant if $P<0.05$.

\section{Results}

\section{Particle characterization}

To determine the effects of nitrogen doping on the absorption spectrum of $\mathrm{TiO}_{2}$, UV-Vis diffuse reflectance experiments were performed. Figure $1 \mathrm{~A}$ shows the UV-Vis diffuse reflectance spectra of $\mathrm{TiO}_{2}$ with various amounts of nitrogen doping. Visible light absorption (from 400 to $800 \mathrm{~nm}$ ) was enhanced with increasing nitrogen doping. Figure $1 \mathrm{~B}$ shows Tauc plots of the UV-Vis absorption data, which are used to determine the bandgap of each sample. The bandgap was $3.11 \mathrm{eV}$ for undoped, $1 \mathrm{~N}-\mathrm{TiO}_{2}$, and $1.25 \mathrm{~N}-\mathrm{TiO}_{2}$. This shifted to $2.99 \mathrm{eV}$ for $1.5 \mathrm{~N}-\mathrm{TiO}_{2}$. Because of the adequate visible absorption by $1.25 \mathrm{~N}_{-} \mathrm{TiO}_{2}$, and the problems with ignition of the $1.5 \mathrm{~N}_{-} \mathrm{TiO}_{2}$ sample, all further experiments were carried out with $1.25 \mathrm{~N}-\mathrm{TiO}_{2}$.

To determine whether the addition of nitrogen affected the final crystal structure of the particles, X-ray diffraction 

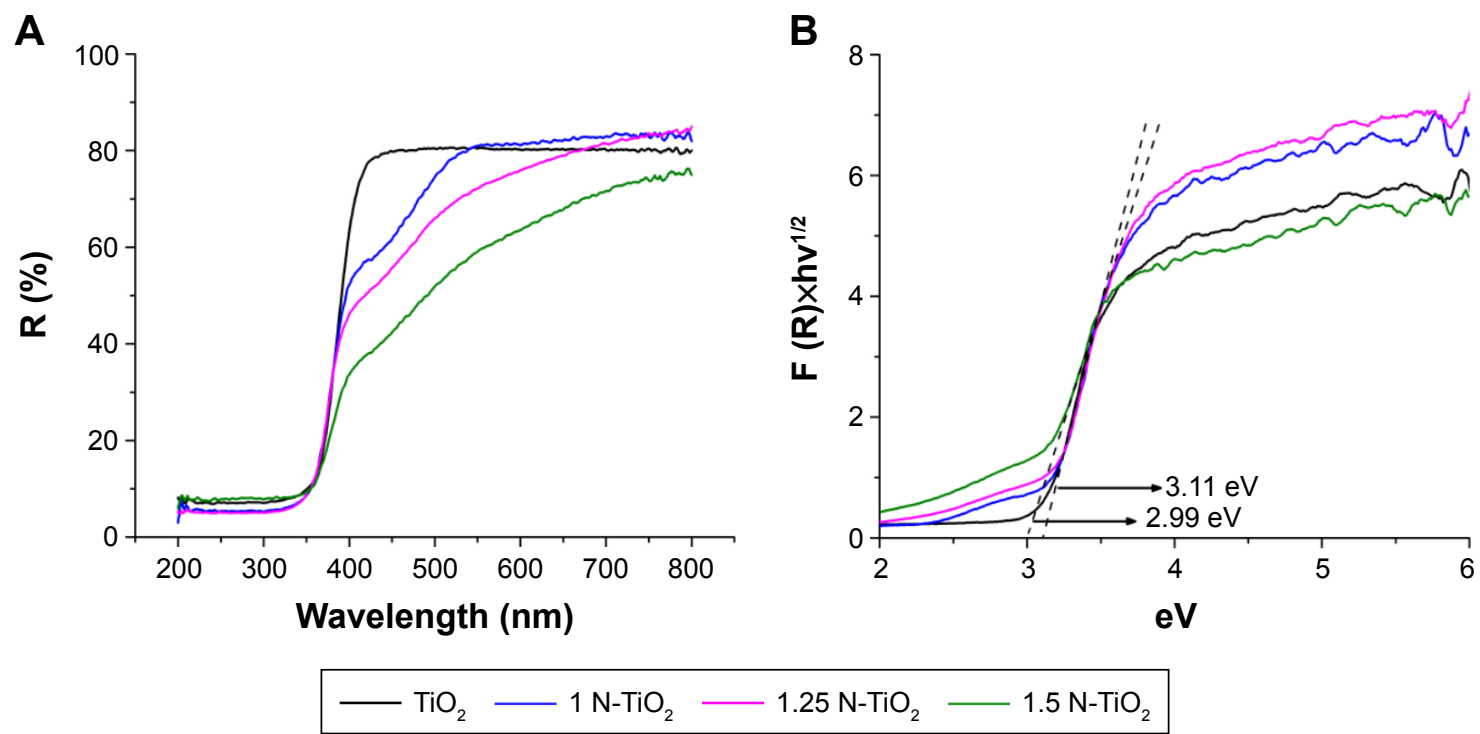

Figure I UV-Visible light absorption spectra of $\mathrm{TiO}_{2}$ with increasing nitrogen content. Note: (A) UV-Vis reflectance spectra and (B) Tauc plots of pure $\mathrm{TiO}_{2}$ and $\mathrm{N}-\mathrm{TiO}_{2}$. Abbreviations: UV, ultraviolet; Vis, visible.

patterns of undoped $\mathrm{TiO}_{2}$ and $\mathrm{N}-\mathrm{TiO}_{2}$ were measured. These are shown in Figure 2 with anatase and rutile $\mathrm{TiO}_{2}$ peaks labeled as "a" and "r", respectively. It is clear from the peak assignments that nitrogen doping resulted in the formation of primarily rutile phase $\mathrm{TiO}_{2}$, while undoped $\mathrm{TiO}_{2}$ was primarily anatase.

Particle size was determined by TEM. The TEM images shown in Figure 3 indicate irregular particle sizes and strong aggregation, which did not break apart after extensive sonication. Both the undoped (Figure $3 \mathrm{~A}$ and $\mathrm{B}$ ) and $1.25 \mathrm{~N}^{-\mathrm{TiO}_{2}} \mathrm{NP}$ samples (Figure $3 \mathrm{C}$ ) consisted of aggregates

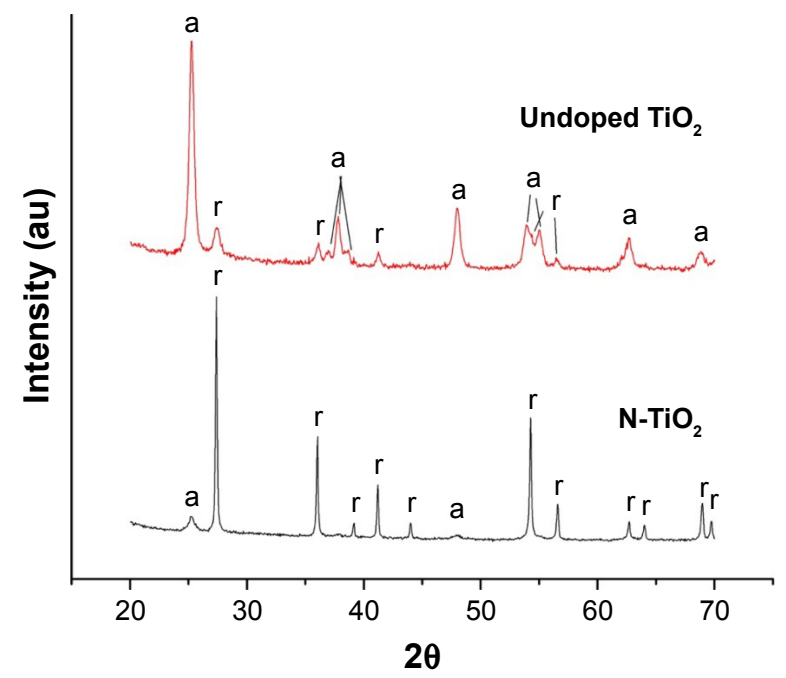

Figure 2 X-ray diffraction patterns of undoped and doped $1.25 \mathrm{~N}-\mathrm{TiO}_{2}$. Note: Anatase phase titania peaks are marked "a", rutile phase titania peaks are marked " $r$ ". ranging from 100 to $300 \mathrm{~nm}$, made up of smaller primary particles: $33.1 \pm 10.3 \mathrm{~nm}$ for undoped $\mathrm{TiO}_{2}$ and $21.8 \pm 9.6 \mathrm{~nm}$ for $1.25 \mathrm{~N}-\mathrm{TiO}_{2}$.

The influence of nitrogen doping on the surface property of $\mathrm{TiO}_{2}$ was explored with zeta potential versus $\mathrm{pH}$ titrations. The isoelectric point (IEP), or the $\mathrm{pH}$ at which the particles have a zero zeta potential, was determined to be at $\mathrm{pH} 5.2$ for undoped $\mathrm{TiO}_{2} \mathrm{NPs}$, while the $\mathrm{N}-\mathrm{TiO}_{2} \mathrm{NPs}$ had the IEP shifted to a lower $\mathrm{pH}$ of 4 .

EPR spectra were measured to specifically identify the radical species generated from particles upon exposure to visible light (approximately 400-675 nm). Figure 4 shows the hydroxyl adducts formed from $1.25 \mathrm{~N}^{-\mathrm{TiO}_{2}}$ in the presence of DMPO under light irradiation. The concentration of $\mathrm{N}_{-} \mathrm{TiO}_{2}$ was $136 \mathrm{mg} / \mathrm{mL}$. No EPR signal was observed without irradiation (Figure 4A), while the signal formation was evident postirradiation (Figure 4B), which matched the simulation data for hydroxyl radical (Figure 4C).

Superoxide adduct has been shown to persist longer in DMSO than in aqueous solution..$^{33}$ Therefore, an experiment was carried out in DMSO to investigate $\mathrm{O}_{2}{ }^{--}$generation. Also, in order to determine the potential role of dissolved $\mathrm{O}_{2}$ in $\mathrm{O}_{2}{ }^{--}$generation, the experiments were performed with air, $\mathrm{Ar}$, or $\mathrm{O}_{2}$ bubbling throughout the suspension.

Figure 5 shows the EPR using $\mathrm{N}-\mathrm{TiO}_{2} \mathrm{NPs}$ in the presence of DMSO. No EPR signal was observed before irradiation, as shown in Figure 5A. The spectra for both air- and $\mathrm{O}_{2}$-bubbled suspensions in the presence of irradiation (Figure 5B) are characterized by the presence of carbon-centered radical as 

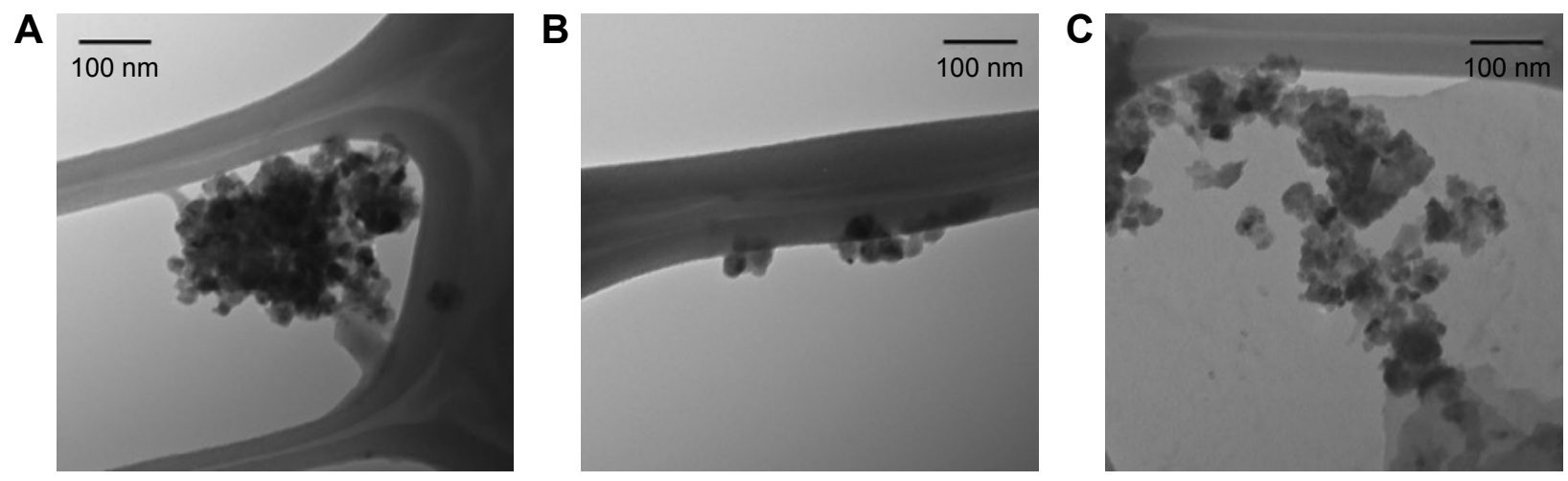

Figure 3 TEM images of (A, B) undoped $\mathrm{TiO}_{2}$ and (C) $1.25 \mathrm{~N}-\mathrm{TiO}_{2}$. Abbreviation: TEM, transmission electron microscopy.

${ }^{\circ} \mathrm{CH}_{3}$ and $\mathrm{O}_{2} \cdot-$ (as ${ }^{\bullet} \mathrm{OOH}$ adducts), as shown in the simulated spectra in Figure 5C.

\section{Biocompatibility and antibacterial studies}

To investigate the biocompatibility of $\mathrm{N}^{-\mathrm{TiO}_{2}} \mathrm{NPs}$ with hGEPs, the oxidative stress response of hGEPs after exposure to $\mathrm{N}-\mathrm{TiO}_{2} \mathrm{NPs}$ under ambient light or $485 \mathrm{~nm}$ blue light was

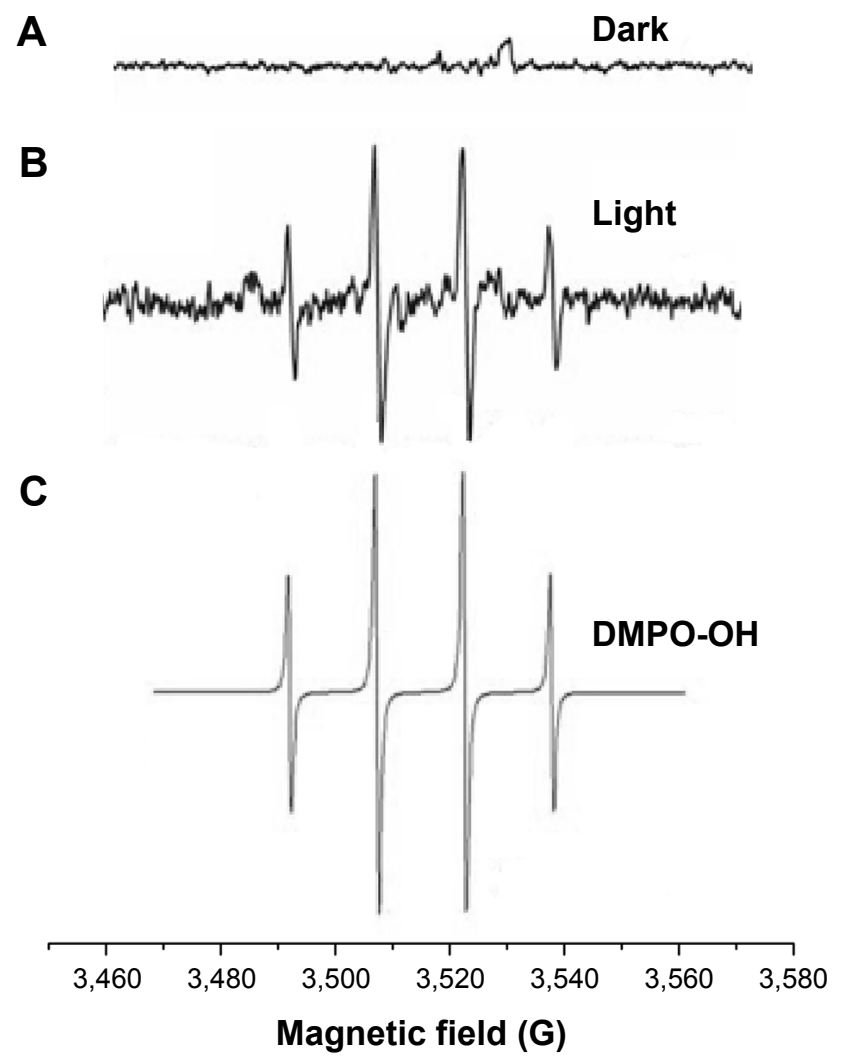

Figure 4 DMPO spin-trapping EPR spectra of $1.25 \mathrm{~N}-\mathrm{TiO}_{2}$ aqueous solutions under (A) dark conditions, (B) visible light irradiation, and (C) DMPO simulation (DMPOOH: $\mathrm{a}_{\mathrm{N}}=\mathrm{a}_{\beta-\mathrm{H}}=14.9 \mathrm{G}$ ) Lit: (DMPO-OH: $\left.\mathrm{a}_{\mathrm{N}}=\mathrm{a}_{\beta-\mathrm{H}}=14.9 \mathrm{G}\right) .^{32}$

Abbreviations: DMPO, 5,5-dimethyl-I-pyrroline- $N$-oxide; EPR, electron paramagnetic resonance. determined by a fluorescence ROS assay. Figure 6 illustrates the ROS production of hGEPs after exposure to $\mathrm{N}-\mathrm{TiO}_{2}$ NPs under ambient light (Figure 6A) and $485 \mathrm{~nm}$ blue light (Figure 6B). The cells produced ROS in response to blue light in the absence of $\mathrm{N}^{-\mathrm{TiO}_{2}} \mathrm{NPs}$. This was accounted for by normalizing NP-exposed cells to the unexposed controls for both time points and light treatments. ROS generation significantly increased in a dose-dependent manner in the presence of blue light treatment.

To determine if $\mathrm{N}-\mathrm{TiO}_{2} \mathrm{NP}$ and light treatment caused cytotoxicity, as indicated by decreases in cellular metabolism in hGEPs, WST-1 assays, which measure the mitochondrial activity, were performed (Figure 7). Cells were treated with increasing concentrations of $\mathrm{N}-\mathrm{TiO}_{2} \mathrm{NPs}$ and immediately exposed to either blue light or ambient light for 60 minutes. Following light exposure, the NPs were aspirated and cellular metabolism was then quantified at 3 (Figure 7A) and 24 hours (Figure 7B) postexposure. After 3 hours, the hGEPs exposed to $\mathrm{N}-\mathrm{TiO}_{2}$ and blue light exhibited significant increases in cellular metabolism when compared to the hGEPS exposed to blue light only. Treatment with $\mathrm{N}-\mathrm{TiO}_{2} \mathrm{NPs}$ and ambient light resulted in a slight, yet nonsignificant increase in proliferation as well. Cellular metabolism was significantly elevated in cells exposed to 50 and $100 \mu \mathrm{g} / \mathrm{mL} \mathrm{N}-\mathrm{TiO}_{2} \mathrm{NPs}$ for 24 hours, irrespective of light treatment. It appears that $\mathrm{N}-\mathrm{TiO}_{2} \mathrm{NPs}$ stimulated cellular metabolism at low and intermediate concentrations, but were not cytotoxic at any concentration tested.

To investigate the potential antibacterial effect of $\mathrm{N}-\mathrm{TiO}_{2}$ NPs and light treatments, the colony counts of E. coli after a 60-minute exposure to ambient or blue light in the presence or absence of $\mathrm{N}-\mathrm{TiO}_{2} \mathrm{NPs}$ were quantified (Figure 8). Treatment with blue light alone resulted in a significant decrease in E. coli colonies. Also, a significant dose-dependent decrease 
A

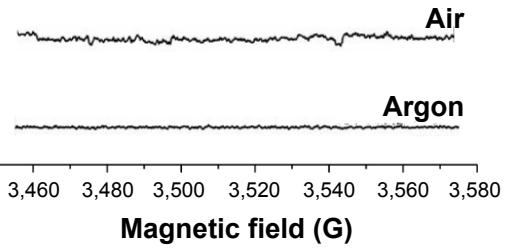

B
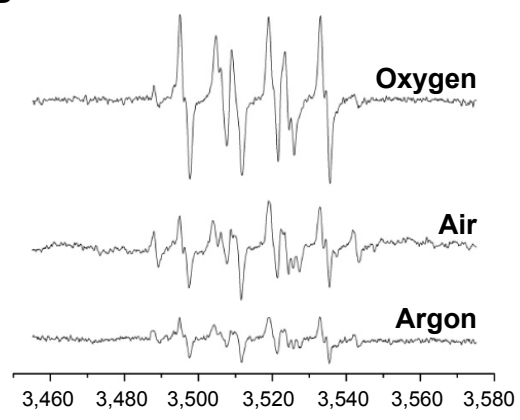

Magnetic field (G)
C
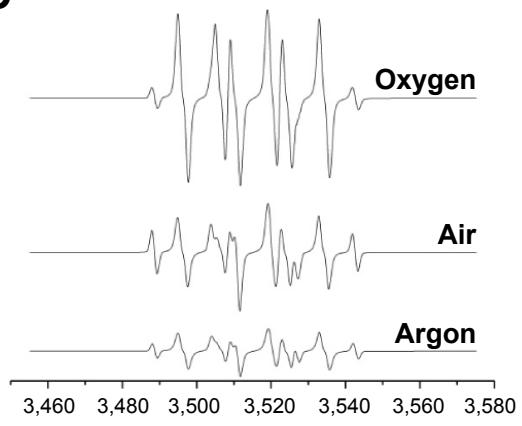

Magnetic field (G)

Figure 5 EPR spectra with I.25 N-TiO ${ }_{2}$ in DMPO/DMSO solutions with bubbling of oxygen, air, and argon in (A) dark condition (B) under visible irradiation, and (C) simulated spectra. DMPO-OOH: $\mathrm{g}=2.0055, \mathrm{a}_{\mathrm{N}}=13.9 \mathrm{G}, \mathrm{a}_{\beta-\mathrm{H}}=10.1 \mathrm{G}, \mathrm{a}_{\gamma-\mathrm{H}}=1.4 \mathrm{G}$; DMPO-alkyl: $\mathrm{g}=2.0053, \mathrm{a}_{\mathrm{N}}=15.8 \mathrm{G}, \mathrm{a}_{\beta \cdot \mathrm{H}}=22.4 \mathrm{G}, \mathrm{a}_{\gamma \cdot \mathrm{H}}=0.6 \mathrm{G}$.

Notes: Literature values: (DMPO-OOH in DMSO: $\mathrm{a}_{\mathrm{N}}=12.7 \mathrm{G}, \mathrm{a}_{\beta-\mathrm{H}}=10.3 \mathrm{G}, \mathrm{a}_{\gamma-\mathrm{H}}=1.3 \mathrm{G}$; DMPO- $\mathrm{CH}_{3}$ in water/DMSO: $\mathrm{a}_{\mathrm{N}}=16.1 \mathrm{G}, \mathrm{a}_{\beta-\mathrm{H}}=23.0 \mathrm{G}$ ). ${ }^{32}$ Simulations correspond to \% compositions of $\%$ alkyl- $\% \mathrm{OOH}$ adducts of $7 \%-93 \%$ in oxygen, $17 \%-83 \%$ in air, and $12 \%-88 \%$ in argon.

Abbreviations: DMPO, 5,5-dimethyl-I-pyrroline-N-oxide; DMSO, dimethyl sulfoxide; EPR, electron paramagnetic resonance.

in bacterial survival was noted when E. coli were exposed to blue light and $\mathrm{N}-\mathrm{TiO}_{2} \mathrm{NPs}$, when compared to exposure under ambient light conditions.

To confirm the antibacterial effect of $\mathrm{N}^{-\mathrm{TiO}_{2}} \mathrm{NPs}$, an additional set of $\mathrm{N}-\mathrm{TiO}_{2} \mathrm{NPs}$ and light exposures were performed, and E. coli were then subjected to live/dead staining. These confocal fluorescence microscopy studies demonstrated changes in bacterial viability in response to NP exposure. The images shown in Figure 9 reveal a general increase in dead bacteria (red) compared to live bacteria (green) with increasing particle concentration. Damaged bacteria appear to swell and undergo changes in morphology in response to light and particle exposure.

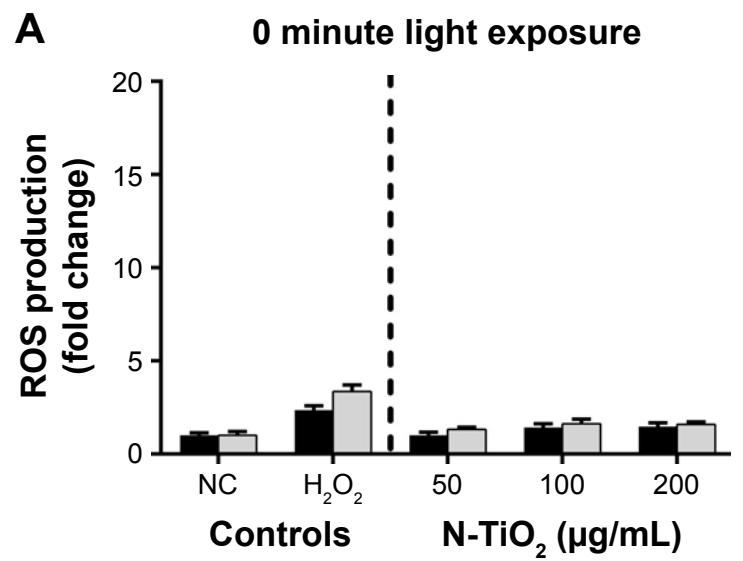

\section{Discussion Effect of nitrogen doping on $\mathrm{TiO}_{2}$ structure}

Consistent with literature reports, ${ }^{18-21}$ nitrogen doping of $\mathrm{TiO}_{2}$ resulted in absorption extending well into the visible range of wavelengths. The extent of absorption in the visible range of wavelengths was concentration dependent. Adding more nitrogen precursor (ethylmethylamine) resulted in increased visible light absorbance (Figure 1).

There are conflicting literature reports on the mechanism of blue light absorption of N-doped titania. Shifts in the bandgap of $\mathrm{TiO}_{2}$ have been reported upon nitrogen doping: from 3.45 to $2.75 \mathrm{eV}^{18}$ and from 3.2 to $2.4 \mathrm{eV} .{ }^{34}$ Other reports

\section{B $\quad 60$ minutes light exposure}

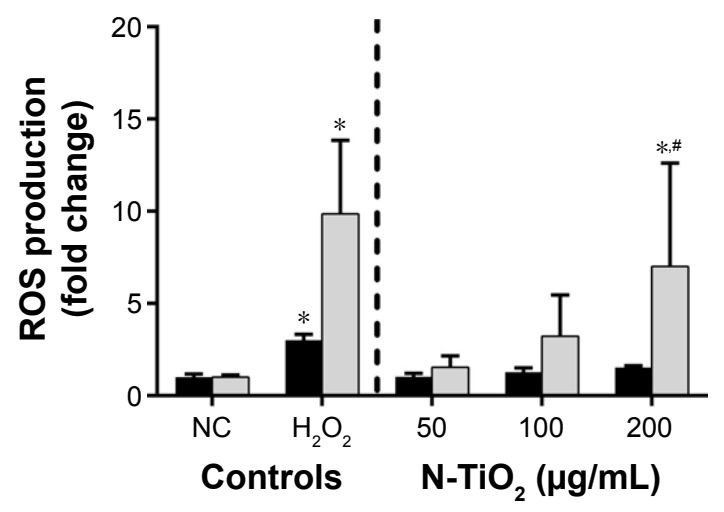

Ambient light $\square$ Blue light

Figure 6 hGEP generation of ROS.

Notes: (A) Fold change of ROS production at 0 minute exposure to blue light and ambient light. Exposure to N-TiO ${ }_{2} \mathrm{NPs}$ normalized to PBS blank. (B) Fold change of

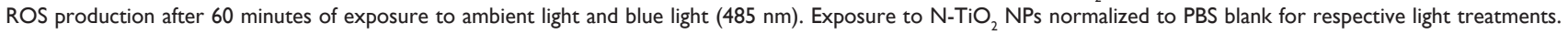
*Significant difference $(P<0.05 ; n=3)$ between respective NC (light-exposed only) and $\mathrm{N}^{-T i O_{2}}$-treated cells. "Significant difference $(P<0.05 ; n=3)$ among light treatments at the same NP exposure concentration.

Abbreviations: hGEP, human gingival epithelial cells; NC, negative control; NPs, nanoparticles; PBS, phosphate-buffered saline; ROS, reactive oxygen species. 
A

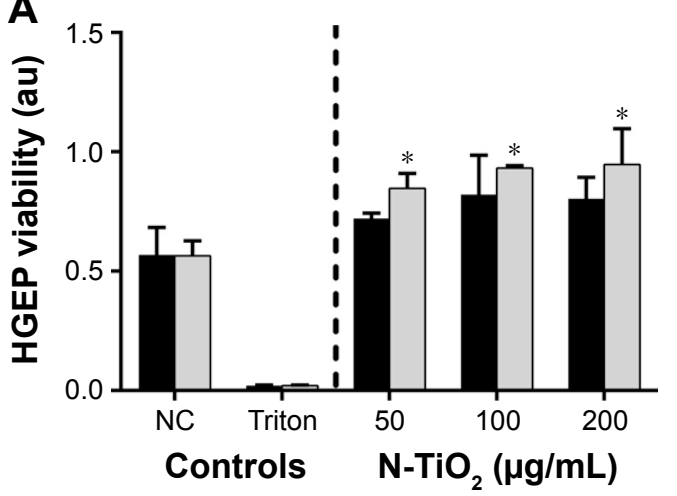

B

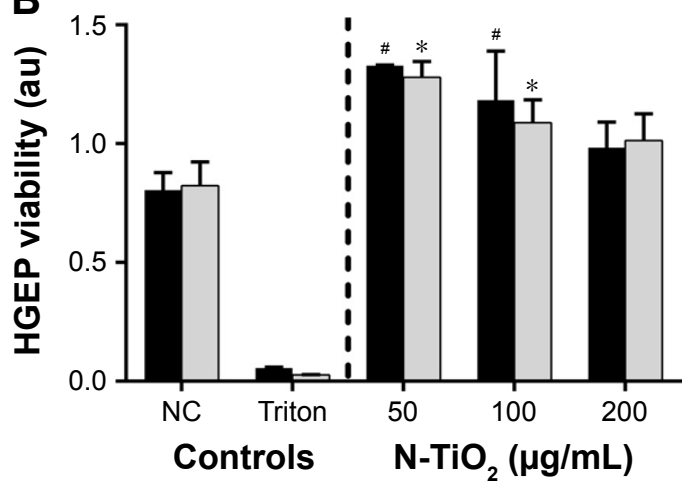

Ambient light $\square$ Blue light

Figure 7 Cellular metabolic responses in hGEPs after $\mathrm{N}-\mathrm{TiO}_{2} \mathrm{NP}$ and light exposures.

Notes: (A) 3 hours after light and $\mathrm{N}-\mathrm{TiO}_{2} \mathrm{NP}$ exposure. (B) 24 hours after light and $\mathrm{N}-\mathrm{TiO}_{2} \mathrm{NP}$ exposure. *Significant difference between blue light-exposed, non-NPtreated NC and NP treatment. "Significant difference between ambient light-exposed, non-NP-treated NC and NP treatment.

Abbreviations: hGEPs, human gingival epithelial cells; NC, negative control; NP, nanoparticle.

indicate that the bulk material bandgap does not significantly shift, and that the absorption of blue light is instead the result of a variety of states at the valence band edge attributed to titanium-site vacancies and undercoordinated oxygen ions. ${ }^{19,21}$ Generally, nitrogen doping by substitution into the crystal structure results in lower energy states closer to the original bandgap, while doping by chemisorption and interstitial incorporation results in deeper trap states. This has generally been found to be dependent on the synthetic method and the concentration of nitrogen precursor, with lower concentrations resulting in substitution and higher concentrations resulting in chemisorption and interstitial doping. ${ }^{35}$

The UV-Vis absorption spectra presented in Figure 1 provide evidence that the increased visible light absorption

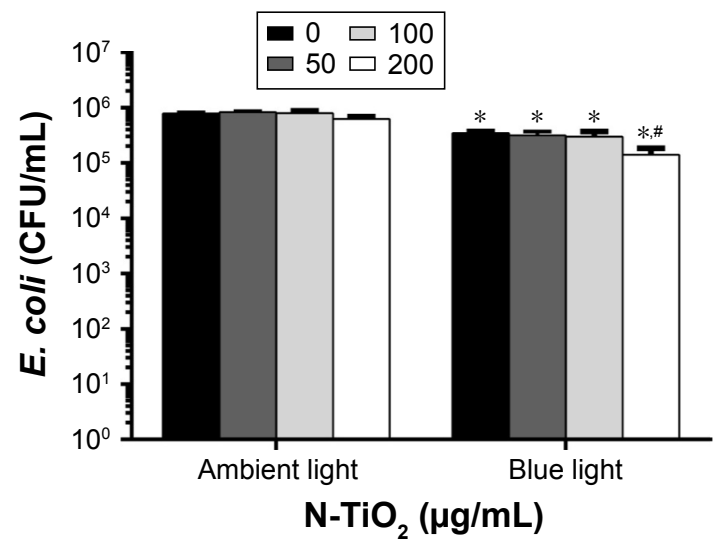

Figure 8 Colony counts of Escherichia coli after exposure to I.25 N-TiO 2 particles and I hour of either ambient room light or blue light.

Notes: Bacteria were suspended in PBS during light treatment at a concentration of approximately $10^{5}$, incubated at $37^{\circ} \mathrm{C}$ for 5 hours, diluted $\mathrm{I}: 10,000$, and plated on lysogeny agar. *Significant difference between blue light-exposed, non-NP-treated NC and NP treatment. "Significant difference between ambient light-exposed, nonNP-treated NC and NP treatment.

Abbreviations: CFU, colony forming units; PBS, phosphate-buffered saline; NC, negative control; NP, nanoparticle.
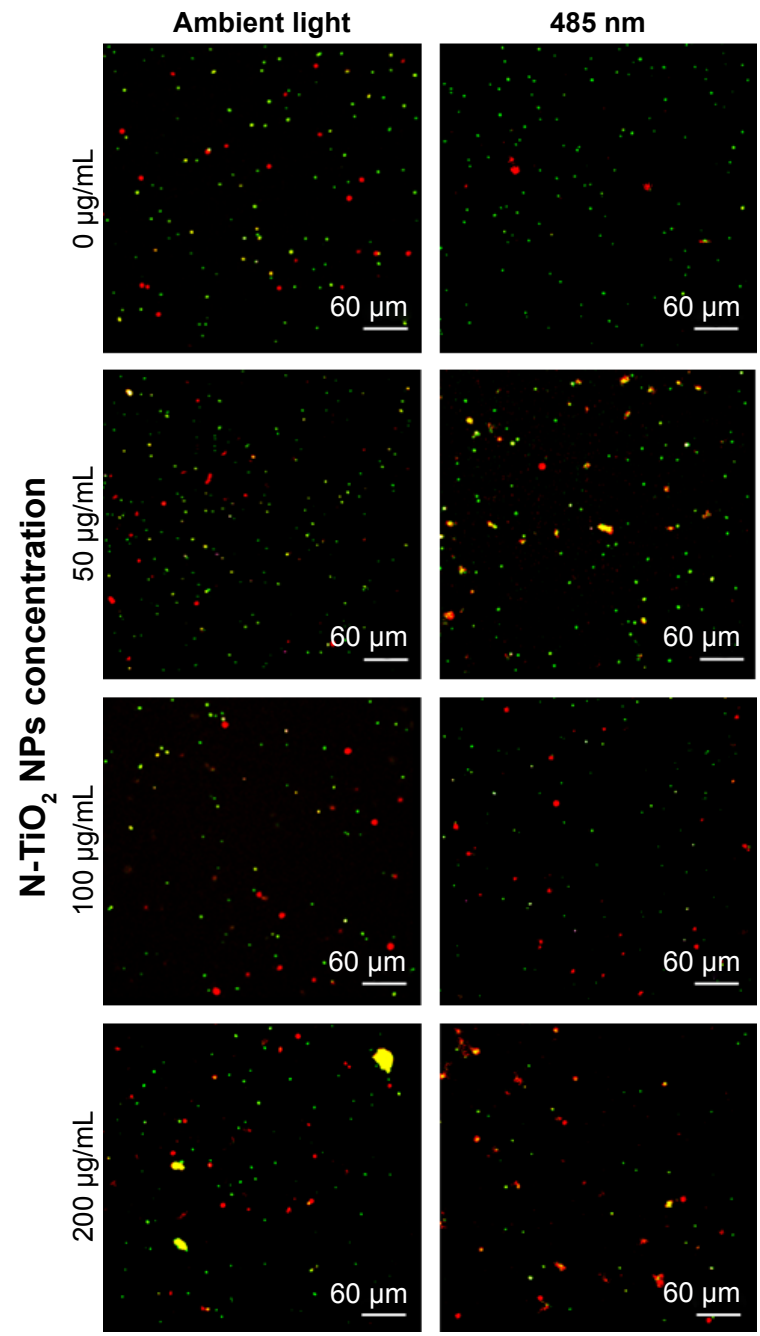

Figure 9 Confocal fluorescence microscopy images of live/dead stained Escherichia coli following exposure to $\mathrm{N}-\mathrm{TiO}_{2} \mathrm{NPs}$ under either ambient light or I hour of exposure to blue light $(485 \mathrm{~nm})$.

Notes: Images were taken using a $20 \times$ objective. Live bacteria are stained green, while the dead bacteria are stained red.

Abbreviation: NPs, nanoparticles. 
in this synthesis can be attributed to valence band trap states. Most of the samples showed no shift in the main bandgap of the material when calculated by Tauc plots $(3.11 \mathrm{eV})$, but did show a tail extending into lower energies characteristic of trap state formation. The Tauc plot calculation for $1.5 \mathrm{~N}_{-} \mathrm{TiO}_{2}$ $(2.99 \mathrm{eV})$ appears to be skewed lower by the increasing amplitude of the trap state peak relative to the main bandgap.

The TEM images presented in Figure 3 show nanosized primary particles of approximately $20-30 \mathrm{~nm}$ agglomerated into larger 200-300 nm aggregate particles. It should be noted that the aggregation state of the particles can impact their toxicity, as they have a larger effective hydrodynamic radius than the initial primary particles. ${ }^{36}$ As some aggregation was observed, it will be imperative to control dispersal when considering the biological applications for $\mathrm{N}_{-} \mathrm{TiO}_{2}$ NPs as the aggregation state may alter the biocompatibility of the final material.

From zeta potential $\mathrm{pH}$ titration data (Figure 10), we find that undoped $\mathrm{TiO}_{2}$ particles had an IEP of $\mathrm{pH}$ 5.2. This matches well with literature: anatase $\mathrm{TiO}_{2}$ particles were found to have an IEP between $\mathrm{pH} 5$ and 6 , depending on their size. ${ }^{37}$ The IEP of $1.25 \mathrm{~N}-\mathrm{TiO}_{2}$ shifted to a $\mathrm{pH}$ of 4 . Literature reports show that the crystal structure of titania does not affect the IEP, ${ }^{37}$ meaning this shift was not due to the transformation to rutile phase. Nitrogen doping has been shown to decrease the zeta potentials and IEP of $\mathrm{TiO}_{2} \cdot{ }^{34,38} \mathrm{We}$, therefore, conclude that the change in IEP for $\mathrm{N}-\mathrm{TiO}_{2}$ in the present study was due to the addition of nitrogen functionality to the surface.

Next we investigated the ability of the synthesized $\mathrm{N}-\mathrm{TiO}_{2}$ NPs to generate free radicals, which could potentially be exploited to make them an effective antibacterial agent. The appearance of EPR signals upon light irradiation in the presence of $\mathrm{N}-\mathrm{TiO}_{2} \mathrm{NPs}$ is attributed to the formation

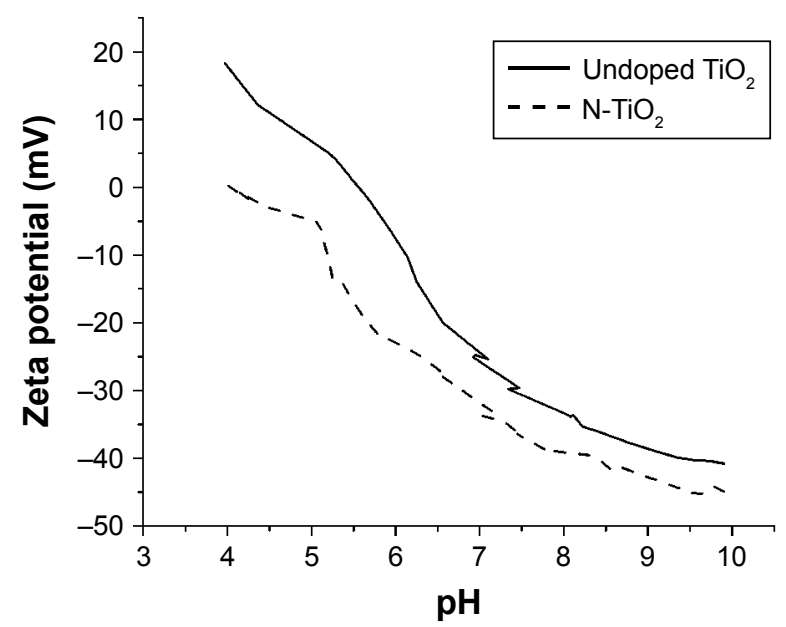

Figure 10 Zeta potential titration versus $\mathrm{pH}$ for undoped $\mathrm{TiO}_{2} \mathrm{NPs}$ and $\mathrm{N}-\mathrm{TiO}_{2} \mathrm{NPs}$. Abbreviation: NPs, nanoparticles. of ${ }^{\bullet} \mathrm{OH} .{ }^{39}$ The formation of $\mathrm{O}_{2}{ }^{\bullet-}$ was not observed due to the short half-life of DMPO- $\mathrm{O}_{2} \mathrm{H}$ which decomposes to DMPO-OH, or the fast dismutation of $\mathrm{O}_{2}{ }^{--}$to form $\mathrm{H}_{2} \mathrm{O}_{2}$ and the subsequent metal-catalyzed homolytic cleavage of $\mathrm{H}_{2} \mathrm{O}_{2}$ to ${ }^{\circ} \mathrm{OH}$ to form DMPO-OH. ${ }^{40}$ Superoxide adduct of DMPO has been shown to be more persistent in $\mathrm{DMSO}^{41}$; hence, spin trapping was performed in aqueous DMSO solution. Comparison of the relative levels of radicals formed in air- versus $\mathrm{O}_{2}$-bubbled suspensions shows higher levels of $\mathrm{O}_{2}{ }^{--}$adduct in $\mathrm{O}_{2}$-bubbled system (93\%) than with air bubbling (83\%) while higher ${ }^{\circ} \mathrm{CH}_{3}$ level was observed in air-bubbling $(17 \%)$ than in $\mathrm{O}_{2}(7 \%)$ and that these signals are significantly decreased with Ar-bubbling.

\section{Biocompatibility and antibacterial activity of $\mathrm{N}-\mathrm{TiO}_{2} \mathrm{NPs}$}

Advancements in the materials engineering field have led to the release of hundreds of consumer products that contain nanomaterials. ${ }^{42}$ Applications capitalizing on the unique ability of $\mathrm{TiO}_{2}$ NPs to form ROS under UV light irradiation are of particular interest. However, UV light is damaging and repeated exposure has been linked to skin damage and tumors caused directly by UV irradiation and indirectly through oxidative stress mechanisms and uncontrolled ROS formation. ${ }^{43}$ Furthermore, while the cytotoxicity and oxidative stress responses after exposure to undoped $\mathrm{TiO}_{2}$ have been extensively studied, ${ }^{44-47}$ the biological effects of $\mathrm{N}-\mathrm{TiO}_{2} \mathrm{NPs}$ exposure are less understood. Thus, in addition to thoroughly characterizing the properties of $\mathrm{N}-\mathrm{TiO}_{2} \mathrm{NPs}$ in a cell-free environment, we also sought to elucidate the antibacterial effects of $\mathrm{N}-\mathrm{TiO}_{2}$ NPs and determine their initial biocompatibility in a normal human cell culture model.

The ROS assays (Figure 6) demonstrate that $\mathrm{N}-\mathrm{TiO}_{2} \mathrm{NPs}$ exposed to blue light induce dose-dependent ROS generation in hGEPs compared to PBS-negative controls. There was a significant change in ROS production between ambient and blue light treatments after exposure to the highest dosage $(200 \mu \mathrm{g} / \mathrm{mL})$ of $\mathrm{N}-\mathrm{TiO}_{2}$ NPs. Although there are relatively few investigations which report on ROS production of $\mathrm{N}-\mathrm{TiO}_{2}$ NPs in mammalian cell models, our ROS results match those described in Li et al's report, ${ }^{48}$ which compared the cytotoxicity of undoped and $\mathrm{N}$-doped $\mathrm{TiO}_{2} \mathrm{NPs}$ in $\mathrm{HeLa}$ cells. In the aforementioned studies, irradiation with blue light (400-440 nm) for up to 5 minutes resulted in substantial increases in total ROS as well as superoxide and hydroxyl radical formation at similar concentrations to those used in our study. As demonstrated through EPR (Figures 4 and 5) studies, the primary ROS generated under visible light exposure were hydroxyl and superoxide radicals. However, there 
are conflicting literature reports on the production of ROS by nitrogen-doped $\mathrm{TiO}_{2}$. Some reports agree with our finding that superoxide radicals are produced, ${ }^{30,48}$ while others indicate that carbon-centered radicals are produced. ${ }^{19}$ Nonetheless, the presence of free radicals indicates that cells may be exposed to conditions that promote oxidative stress, which could result in adverse cellular responses including cell death. To begin to understand what, if any, effects the $\mathrm{N}-\mathrm{TiO}_{2} \mathrm{NPs}$ may have on normal human cells, metabolic activity measurements in hGEPs were performed immediately (3 hours) or after a 24-hour recovery period.

Interferences have been reported for several types of assays used to estimate cytotoxicity, proliferation, and mitochondrial activity. Specifically, there is a known binding activity between $\mathrm{TiO}_{2}$ and lactate dehydrogenase, which is the commonly used cytotoxicity assay. ${ }^{49,50} \mathrm{TiO}_{2}$ also caused noncellular reduction in the 3-(4,5-dimethylthiazol-2-yl)2,5-diphenyltetrazolium bromide assay. ${ }^{51}$ In the current study, WST-1 was selected as an indicator of metabolic activity assay because cell-free testing using NPs alone and the WST-1 reagent did not result in any artifacts or interferences, which suggests that WST-1 is a suitable indicator of cellular metabolism and, therefore, can be used as an indirect measure of cellular viability. The metabolic activity of hGEPs increased significantly within 3 hours of light and $\mathrm{N}-\mathrm{TiO}_{2}$ NP exposure, which suggests that the ROS may induce enhanced metabolism in response to these stimuli, due to the cells actively working to neutralize any oxidative stress associated with this treatment. Interestingly, the same trend was noted for cells exposed to $\mathrm{N}-\mathrm{TiO}_{2} \mathrm{NPs} 24$ hours after irradiation with ambient or blue light, except at the highest concentration tested. These data suggest that $\mathrm{N}-\mathrm{TiO}_{2} \mathrm{NPs}$ may generate ROS at levels that stimulate mitochondrial activity and increased cellular metabolism, but the cells are equipped with enough antioxidant mechanisms to protect them and preserve their viability. These data are in agreement with Behzadnia et al, ${ }^{52}$ who demonstrated no adverse effects when fabrics treated with $\mathrm{N}-\mathrm{TiO}_{2}$ NPs were exposed to normal human dermal fibroblasts. Yet, the findings in the present study are also in contrast with the viability and cellular responses reported in other studies. As described earlier, Li et al reported significant increases in ROS. ${ }^{48}$ However, in their study, they also demonstrate decline in HeLa cell mitochondrial membrane potential and significant increases in intracellular $\mathrm{Ca}^{2+}$ levels, both of which are indicative of severe cytotoxicity. Furthermore, in a previous study, the same group demonstrated that $\mathrm{N}-\mathrm{TiO}_{2} \mathrm{NPs}$ are capable of inducing cytotoxicity and micronuclei formation in three cancer cell lines. ${ }^{53}$ There are several notable differences between our study and the studies of Li. One such difference is the intensity and duration of light used among the studies. The present study used $12.85 \mathrm{~mW} / \mathrm{cm}^{2}$ for 60 minutes, and $\mathrm{Li}$ irradiated with $12 \mathrm{~mW} / \mathrm{cm}^{2}$ for 4 hours or $40 \mathrm{~mW} / \mathrm{cm}^{2}$ for up to 5 minutes in his studies. Also, the particles were prepared using ammonia gas as a nitrogen source. Finally, the cell culture models employed by these authors were cancer cell lines, which often have various susceptibilities to different stimuli, compared with the normal cells used in this study. As such, the work presented here indicates that while the $\mathrm{N}-\mathrm{TiO}_{2}$ NPs induce ROS, the normal cells may be equipped with adequate protective mechanisms to ensure their survival. Further studies are warranted to investigate potential cellular responses after repeated or chronic exposure to both light and $\mathrm{N}-\mathrm{TiO}_{2}$ NPs.

Multiple studies have demonstrated the antibacterial effects of undoped $\mathrm{TiO}_{2}$ NPs alone and under UV irradiation. ${ }^{14,54,55}$ Several groups have demonstrated effective bacterial and fungal reduction using $\mathrm{N}-\mathrm{TiO}_{2} \mathrm{NPs}$ and films. ${ }^{56-58}$ In the present work, a repeatable, dose-dependent $(0-200 \mu \mathrm{g} / \mathrm{mL})$ toxicity toward E. coli resulted upon blue light treatment (Figure 8). An approximately 1-log reduction in bacterial population was observed with the highest concentration of particles. These findings were in agreement with the morphological changes and the decrease in number of viable bacteria observed by confocal microscopy. The antibacterial activity reported here is not as substantial as reported by Cao et al, where 90\% reduction was observed in Lactobacillus acidophilus and Candida albicans. ${ }^{58}$ Their study was performed using a much longer 24-hour exposure to visible light and a thin film surface of nitrogen-doped titania. Furthermore, it is possible that ROS scavenging occurred, minimizing the potency of oxidative stress.

\section{Conclusion}

The $\mathrm{N}_{-} \mathrm{TiO}_{2}$ NPs synthesized by this method produced ROS (hydroxyl and superoxide) capable of significantly reducing bacterial counts while maintaining the viability of human epithelial cells, in the presence of water, oxygen, and visible light. Subsequent experiments will determine if the $\mathrm{N}_{-} \mathrm{TiO}_{2}$ NPs are toxic to biofilm-forming bacteria ( $S$. mutans) when incorporated into a dental resin composite material. While blue light exposure alone induced ROS production in hGEPs, this is not considered prohibitive toward the eventual use of these particles in dental applications. A current barrier to the 
translation of these particles into a real-life application is the length of light exposure and the depth of light penetration required to achieve an impactful biological effect. One-hour light exposures were required to exhibit antibacterial activity at the concentrations used in solution against planktonic bacteria. In the resin formulation, particle concentrations can be $>50 \%$ by weight of the material. It is expected that light exposure times required to achieve antibacterial activity will be reduced. Therefore, future work is aimed at reducing the irradiation times and enhancing the antibacterial effects while maintaining a balance of oxidative stress that is toxic to bacteria and minimally affecting mammalian cellular responses.

\section{Acknowledgments}

The authors wish to thank Ms Shannon Olsen for her lab managerial assistance and assay refinement efforts and Mr Duane Cox for his expert engineering skills used to construct the light box. The authors also wish to acknowledge Mr Tony Yuan and Mr Matt Morgan for their assistance with processing the confocal images. In addition, the authors thank Dr Amer Tiba for his critical feedback and thoughtful discussion.

\section{Disclosure}

The views expressed in this article are those of the authors and do not necessarily reflect the official policy or position of the Department of the Navy, Department of Defense, or the US Government. Title 17 U.S.C. $\$ 105$ provides that "Copyright protection under this title is not available for any work of the United States Government". Title 17 U.S.C. $\S 101$ defines a US Government work as a work prepared by a military service member or employee of the US Government, as part of that person's official duties. This work was funded by the Naval Medical Research Center's Advanced Medical Development Program using work unit number G1405. Amber Nagy is an employee of the US Government and Andrew Zane, Ann Marie Digeorge Foushee, and Kristin Flores are contracted by the US Government. This work was prepared as part of our official duties. Ranfang Zuo was supported by Fundamental Research Funds for the Central Universities (Grant No 2652013037). The Hungarian National Research, Development and Innovation Office (NKFIH) Grant Nr. K119442 is acknowledged for support of Antal Rockenbauer.

The authors report no other conflicts of interest in this work.

\section{References}

1. McCracken MS, Gordan VV, Litaker MS, et al. A 24-month evaluation of amalgam and resin-based composite restorations: findings from The National Dental Practice-Based Research Network. J Am Dent Assoc. 2013;144(6):583-593.

2. Drummond JL. Degradation, fatigue and failure of resin dental composite materials. J Dent Res. 2008;87(8):710-719.

3. Brunthaler A, König F, Lucas T, Sperr W, Schedle A. Longevity of direct resin composite restorations in posterior teeth. Clin Oral Investig. 2003;7(2):63-70.

4. Li Y, Carrera C, Chen R, et al. Degradation in the dentin-composite interface subjected to multi-species biofilm challenges. Acta Biomater. 2014;10(1).375-383.

5. Mutluay MM, Zhang K, Ryou H, et al. On the fatigue behavior of resin-dentin bonds after degradation by biofilm. J Mech Behav Biomed Mater. 2013;18:219-231.

6. Shen W, Zhang C, Li Q, Zhang W, Cao L, Ye J. Preparation of titanium dioxide nano particle modified photocatalytic self-cleaning concrete. J Clean Prod. 2015;87:762-765.

7. Sakhuja M, Son J, Yang H, Bhatia CS, Danner AJ. Outdoor performance and durability testing of antireflecting and self-cleaning glass for photovoltaic applications. Sol Energ. 2014;110:231-238.

8. Gant RM, Hou Y, Grunlan MA, Coté GL. Development of a self-cleaning sensor membrane for implantable biosensors. J Biomed Mater Res. 2009; 90A(3):695-701.

9. Ohko Y, Utsumi Y, Niwa C, et al. Self-sterilizing and self-cleaning of silicone catheters coated with $\mathrm{TiO} 2$ photocatalyst thin films: a preclinical work. J Biomed Mater Res. 2001;58(1):97-101.

10. Kulkarni M, Mazare A, Gongadze E, et al. Titanium nanostructures for biomedical applications. Nanotechnology. 2015;26(6):062002.

11. Linsebigler AL, Lu G, Yates JT. Photocatalysis on $\mathrm{TiO}_{2}$ surfaces: principles, mechanisms, and selected results. Chem Rev. 1995;95(3): 735-758.

12. Gupta K, Singh RP, Pandey A, Pandey A. Photocatalytic antibacterial performance of $\mathrm{TiO}_{2}$ and $\mathrm{Ag}$-doped $\mathrm{TiO}_{2}$ against $S$. aureus. P. aeruginosa and E. coli. Beilstein J Nanotechnol. 2013;4:345-351.

13. Lee WS, Park YS, Cho YK. Significantly enhanced antibacterial activity of $\mathrm{TiO} 2$ nanofibers with hierarchical nanostructures and controlled crystallinity. Analyst. 2014;140(2):616-622.

14. Joost U, Juganson K, Visnapuu M, et al. Photocatalytic antibacterial activity of nano-TiO2 (anatase)-based thin films: effects on Escherichia coli cells and fatty acids. J Photochem Photobiol B. 2015;142: 178-185.

15. Ermis RB, Yildirim D, Yildiz G, Gormez O. Radiopacity evaluation of contemporary resin composites by digitization of images. Eur J Dent. 2014;8(3):342-347.

16. Wu J, Weir MD, Melo MA, Xu HH. Development of novel self-healing and antibacterial dental composite containing calcium phosphate nanoparticles. J Dent. 2015;43(3):317-326.

17. Huyang G, Sun J. Clinically applicable self-healing dental resin composites. MRS Advances. 2016;1(08):547-552.

18. Jagadale TC, Takale SP, Sonawane RS, et al. N-doped TiO2 nanoparticle based visible light photocatalyst by modified peroxide sol-gel method. J Phys Chem C. 2008;112(37):14595-14602.

19. Mrowetz M, Balcerski W, Colussi AJ, Hoffmann MR. Oxidative power of nitrogen-doped $\mathrm{TiO} 2$ photocatalysts under visible illumination. J Phys Chem B. 2004;108(45):17269-17273.

20. Wang G, Xiao X, Li W, et al. Significantly enhanced visible light photoelectrochemical activity in $\mathrm{TiO} 2$ nanowire arrays by nitrogen implantation. Nano Lett. 2015;15(7):4692-4698.

21. Chen H, Dawson JA. Nature of nitrogen-doped anatase $\mathrm{TiO}_{2}$ and the origin of its visible-light activity. $J$ Phys Chem C. 2015;119(28):15890-15895.

22. Janpetch N, Vanichvattanadecha C, Rujiravanit R. Photocatalytic disinfection of water by bacterial cellulose/N-F co-doped $\mathrm{TiO} 2$ under fluorescent light. Cellulose. 2015;22(5):3321-3335. 
23. Pongwan P, Wetchakun K, Phanichphant S, Wetchakun N. Enhancement of visible-light photocatalytic activity of $\mathrm{Cu}$-doped $\mathrm{TiO} 2$ nanoparticles. Res Chem Intermed. 2016;42:2815-2830.

24. Ashkarran AA, Hamidinezhad H, Haddadi H, Mahmoudi M. Doubledoped $\mathrm{TiO} 2$ nanoparticles as an efficient visible-light-active photocatalyst and antibacterial agent under solar simulated light. Appl Surf Sci. 2014;301:338-345.

25. Sato K, Taguchi H, Maeda T, et al. The primary cytotoxicity in ultraviolet-a-irradiated riboflavin solution is derived from hydrogen peroxide. J Investig Dermatol. 1995;105(4):608-612.

26. Zaleska A. Doped-TiO : a review. Recent Pat Biomed Eng. 2008;2(3): 157-164.

27. Asahi R, Morikawa T, Irie H, Ohwaki T. Nitrogen-doped titanium dioxide as visible-light-sensitive photocatalyst: designs, developments, and prospects. Chem Rev. 2014;114(19):9824-9852.

28. Hernández-Sierra JF, Galicia-Cruz O, Angélica S-A, Ruiz F, PierdantPérez M, Pozos-Guillén AJ. In vitro cytotoxicity of silver nanoparticles on human periodontal fibroblasts. J Clin Pediatr Dent. 2011; 36(1):37-41.

29. Taleghani F, Yaraii R, Sadeghi R, Haghgoo R, Rezvani MB. Cytotoxicity of silver nanoparticles on human gingival epithelial cells: an in-vitro study. Shahid Beheshti Univ Dent J. 2014;32(1):30-36.

30. Fu H, Zhang L, Zhang S, Zhu Y, Zhao J. Electron spin resonance spintrapping detection of radical intermediates in N-doped TiO2-assisted photodegradation of 4-chlorophenol. J Phys Chem B. 2006;110(7): 3061-3065

31. Rockenbauer A, Korecz L. Automatic computer simulations of ESR spectra. Appl Magn Reson. 1996;10(1-3):29-43.

32. Buettner GR. Spin trapping: ESR parameters of spin adducts 1474 1528V. Free Rad Biol Med. 1987;3(4):259-303.

33. Kohno M, Mizuta Y, Kusai M, Masumizu T, Makino K. Measurements of superoxide anion radical and superoxide anion scavenging activity by electron spin resonance spectroscopy coupled with DMPO spin trapping. Bull Chem Soc Jpn. 1994;67(4):1085-1090.

34. Ha S-J, Kim DH, Moon JH. N-doped mesoporous inverse opal structures for visible-light photocatalysts. RSC Adv. 2015;5(95):77716-77722.

35. Viswanathan B, Krishanmurthy KR. Nitrogen incorporation in TiO2: does it make a visible light photo-active material? Int J Photoenergy. 2012;2012:e269654

36. Jiang J, Oberdörster G, Biswas P. Characterization of size, surface charge, and agglomeration state of nanoparticle dispersions for toxicological studies. J Nanopart Res. 2008;11(1):77-89.

37. Suttiponparnit K, Jiang J, Sahu M, Suvachittanont S, Charinpanitkul T, Biswas P. Role of surface area, primary particle size, and crystal phase on titanium dioxide nanoparticle dispersion properties. Nanoscale Res Lett. 2010;6(1):27.

38. Miyauchi M, Ikezawa A, Tobimatsu H, Irie H, Hashimoto K. Zeta potential and photocatalytic activity of nitrogen doped $\mathrm{TiO}_{2}$ thin films. Phys Chem Chem Phys. 2004;6(4):865-870.

39. Villamena FA, Hadad CM, Zweier JL. Kinetic study and theoretical analysis of hydroxyl radical trapping and spin adduct decay of alkoxycarbonyl and dialkoxyphosphoryl nitrones in aqueous media. $J$ Phys Chem A. 2003;107(22):4407-4414.

40. Villamena FA, Merle JK, Hadad CM, Zweier JL. Superoxide radical anion adduct of 5,5-dimethyl-1-pyrroline N-oxide (DMPO). 1. The thermodynamics of formation and its acidity. JPhys Chem A. 2005;109(27): 6083-6088.

International Journal of Nanomedicine

\section{Publish your work in this journal}

The International Journal of Nanomedicine is an international, peerreviewed journal focusing on the application of nanotechnology in diagnostics, therapeutics, and drug delivery systems throughout the biomedical field. This journal is indexed on PubMed Central, MedLine, CAS, SciSearch $®$, Current Contents ${ }^{\circledR} /$ Clinical Medicine,
41. Harbour JR, Hair ML. Detection of superoxide ions in nonaqueous media. Generation by photolysis of pigment dispersions. J Phys Chem. 1978;82(12):1397-1399.

42. Contado C. Nanomaterials in consumer products: a challenging analytical problem. Front Chem. 2015;3:48.

43. Ichihashi M, Ueda M, Budiyanto A, et al. UV-induced skin damage. Toxicology. 2003;189(1-2):21-39.

44. Cai R, Kubota Y, Shuin T, Sakai H, Hashimoto K, Fujishima A. Induction of cytotoxicity by photoexcited $\mathrm{TiO}_{2}$ particles. Cancer Res. 1992;52(8):2346-2348.

45. Wamer WG, Yin JJ, Wei RR. Oxidative damage to nucleic acids photosensitized by titanium dioxide. Free Radic Biol Med. 1997;23(6): 851-858.

46. Shukla RK, Sharma V, Pandey AK, Singh S, Sultana S, Dhawan A. ROS-mediated genotoxicity induced by titanium dioxide nanoparticles in human epidermal cells. Toxicol In Vitro. 2011;25(1):231-241.

47. Shukla RK, Kumar A, Gurbani D, Pandey AK, Singh S, Dhawan A. $\mathrm{TiO}(2)$ nanoparticles induce oxidative DNA damage and apoptosis in human liver cells. Nanotoxicology. 2013;7(1):48-60.

48. Li Z, Pan X, Wang T, Wang PN, Chen JY, Mi L. Comparison of the killing effects between nitrogen-doped and pure $\mathrm{TiO}_{2}$ on HeLa cells with visible light irradiation. Nanoscale Res Lett. 2013;8(1):96.

49. Zaqout MSK, Sumizawa T, Igisu H, Wilson D, Myojo T, Ueno S. Binding of titanium dioxide nanoparticles to lactate dehydrogenase. Environ Health Prev Med. 2012;17(4):341-345.

50. Han X, Gelein R, Corson N, et al. Validation of an LDH assay for assessing nanoparticle toxicity. Toxicology. 2011;287(1-3):99-104.

51. Lupu AR, Popescu T. The noncellular reduction of MTT tetrazolium salt by $\mathrm{TiO}_{2}$ nanoparticles and its implications for cytotoxicity assays. Toxicol In Vitro. 2013;27(5):1445-1450.

52. Behzadnia A, Montazer M, Rashidi A, Mahmoudi Rad M. Rapid sonosynthesis of $\mathrm{N}$-doped nano $\mathrm{TiO}_{2}$ on wool fabric at low temperature: introducing self-cleaning, hydrophilicity, antibacterial/antifungal properties with low alkali solubility, yellowness and cytotoxicity. Photochem Photobiol. 2014;90(6):1224-1233.

53. Li Z, Mi L, Wang PN, Chen JY. Study on the visible-light-induced photokilling effect of nitrogen-doped $\mathrm{TiO}_{2}$ nanoparticles on cancer cells. Nanoscale Res Lett. 2011;6(1):356.

54. Petersen EJ, Reipa V, Watson SS, Stanley DL, Rabb SA, Nelson BC. DNA damaging potential of photoactivated p25 titanium dioxide nanoparticles. Chem Res Toxicol. 2014;27(10):1877-1884.

55. Pleskova SN, Golubeva IS, Verevkin YK. Bactericidal activity of titanium dioxide ultraviolet-induced films. Mater Sci Eng CMater Biol Appl. 2016;59:807-817.

56. Wong MS, Chu WC, Sun DS, et al. Visible-light-induced bactericidal activity of a nitrogen-doped titanium photocatalyst against human pathogens. Appl Environ Microbiol. 2006;72(9):6111-6116.

57. Li Q, Xie R, Li YW, Mintz EA, Shang JK. Enhanced visible-lightinduced photocatalytic disinfection of $E$. coli by carbon-sensitized nitrogen-doped titanium oxide. Environ Sci Technol. 2007;41(14): 5050-5056.

58. Cao S, Liu B, Fan L, Yue Z, Liu B, Cao B. Highly antibacterial activity of $\mathrm{N}$-doped $\mathrm{TiO}_{2}$ thin films coated on stainless steel brackets under visible light irradiation. Appl Surf Sci. 2014;309:119-127.

Journal Citation Reports/Science Edition, EMBase, Scopus and the Elsevier Bibliographic databases. The manuscript management system is completely online and includes a very quick and fair peer-review system, which is all easy to use. Visit http://www.dovepress.com/ testimonials.php to read real quotes from published authors. 